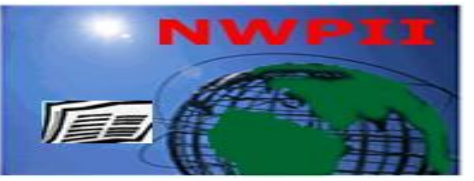

American Journal of Biomedical Sciences

ISSN: 1937-9080

nwpii.com/ajbms

\title{
Regulation of Microvascular Function by Adipose Tissue in Obesity and Type 2 Diabetes: Evidence of an Adipose-Vascular Loop
}

\author{
Hanrui Zhang and Cuihua Zhang
}

Departments of Internal Medicine, Medical Pharmacology \& Physiology and Nutritional Sciences, Dalton

Cardiovascular Research Center, University of Missouri-Columbia, Columbia, MO 65211

*Corresponding Author

Cuihua Zhang, MD, PhD

Division of Cardiovascular Medicine

Department of Internal Medicine, Medical

Pharmacology \& Physiology and Nutritional Science

Dalton Cardiovascular Research Center

University of Missouri - Columbia

Columbia, MO 65211

Phone: 573-882-2427

Fax: 573-884-4232

E-mail address: zhangcu@ missouri.edu

\begin{tabular}{l|l|l} 
Received: 5 January 2009; & Revised: 8 February 2009; & Accepted: 14 February 2009
\end{tabular}

\begin{abstract}
In recent years, the general concept has emerged that chronic low-grade inflammation is the condition linking excessive development of adipose tissue and obesity-associated pathologies such as type 2 diabetes and cardiovascular diseases. Obesity and type 2 diabetes are characterized by a diminished production of protective factors such as adiponectin and increased detrimental adipocytokines such as leptin, resistin, interleukin-6 (IL-6), tumor necrosis factor-alpha (TNF $\alpha$ ), and monocyte chemoattractant protein-1 (MCP-1) by adipose tissue. Moreover, the evidence that the growth of the fat mass is associated with an accumulation of adipose tissue macrophages and T-lymphocytes has raised the hypothesis that the development of an inflammatory process within the growing fat mass is a primary event involved in the genesis of systemic metabolic and vascular alterations. This crosstalk of adipocyte, macrophage, lymphocyte, endothelial cells, and vascular smooth muscle cells contribute to the production of various cytokines, chemokines, and hormone-like factors, which actively participate in the regulation of vascular function by an endocrine and/or paracrine pattern. Thus, the signaling from perivascular adipose to the blood vessels is emerging as a potential therapeutic target for obesity and diabetes-associated vascular dysfunction.
\end{abstract}

Keywords: Inflammation; adipokines; vascular dysfunction; obesity; diabetes mellitus. 


\section{Introduction}

The increased prevalence of obesity and obesity-related cardiovascular risk factors are closely associated with the rising incidence of cardiovascular diseases and type 2 diabetes [1]. The classical perception of adipose tissue as a passive repository of fatty acids has been replaced by the notion that adipose tissue serves as a highly active metabolic and endocrine organ by regulating lipid and glucose metabolism and by producing a large number of cytokines (eg. tumor necrosis factor-alpha $[\mathrm{TNF} \alpha]$ and interleukin-6 [IL-6]), chemokines (eg. IL-8 and monocyte chemoattractant protein-1 [MCP-1]) and hormones (eg. leptin and adiponectin) [2]. These products are called adipokines (originally called adipocytokines or adipose tissue-derived cytokines) [3]. Obesity and diabetes-related vascular dysfunction may well be caused by altered signaling from adipose tissue to blood vessels, as adipokines produced by adipose tissue may affect vascular function [3, 4]. Central adiposity, particularly a greater amount of intraabdominal or visceral fat, contributes to the chronic subclinical inflammation, which is linked to vascular dysfunction and atherosclerosis [5]. An important mechanism in the regulation of inflammation by perivascular adipose is macrophage infiltration [3]. Clinical studies suggested that abdominal adipose macrophage infiltration is associated with systemic arterial dysfunction and insulin resistance in obese subjects [6]. Hormones (leptin, adiponectin) mainly produced by adipocytes also actively participate in the regulation of vascular function and insulin sensitivity [7] Thus, adipose-derived adipokines may play an endocrine and/or paracrine role in the regulation of vascular function in obesity and diabetes. (Figure 1)

This review will discuss the regulation of vascular function by adipose tissue and its relevance to obesity and diabetes-related vascular dysfunction, with a special focus on microvascular function.

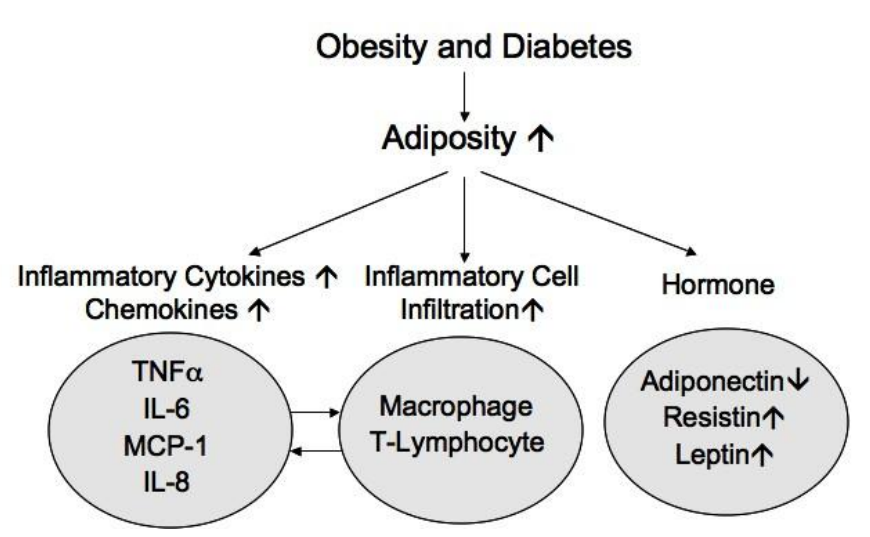

Figure 1. Dysregulation of Adipokines during Obesity and Diabetes. Adipose tissue serves as a highly active metabolic and endocrine organ by producing a large number of cytokines (eg. TNF $\alpha$ and IL-6), chemokines (eg. IL-8 and MCP-1) and hormones (eg. leptin, adiponectin and resistin, etc.). An adverse adipokine expression profile has been suggested in obese and type 2 diabetic patients, which is characterized by a diminished production of protective factors such as adiponectin and increased detrimental adipokines such as leptin, resistin, IL-6, TNF $\alpha$, and MCP-1.

\section{Adipokines Produced by Adipose Tissue}

The fact that adipose tissue releases a wide range of adipokines, growth factors, enzymes, and enzyme substrates linked to vascular injury provides a plausible explanation for the role of fat in vascular disease. TNF $\alpha$, leptin, resistin, IL-1, IL-6, IL-8, and IL-18, visfatin, chemerin, serum amyloid A, MCP-1, macrophage inhibitory factor (MIF), aortic carboxypeptidase, heparin-binding epidermal growth factor-like growth factor (HBEGF), vascular endothelial growth factor (VEGF), transforming growth factor-beta (TGF $\beta$ ), angiotensinogen, cathepsin S, estradiol, cortisol, mineralocorticoid releasing factor, and calcitonin peptides are probable fat-derived prothrombotic, proinflammatory, and proatherosclerotic agents acting in an endocrine and/or paracrine manner. Other adipocyte products such as adiponectin, and interleukin-10 exert antiatherogenic effects [8]. Several studies indicate that different fat depots have differential gene expression pattern and there may be greater production of adipocytokines from 
visceral fat than from subcutaneous fat [9-14]. An adverse adipokine expression profile has also been suggested in adipose of obese human subjects by microarray and real-time polymerase chain reaction (qPCR) analysis $[15,16]$ The composition of perivascular adipose includes adipocyte, fibroblast, fibroblast-like stem cells, macrophages, and T-lymphocyte [3] Over $90 \%$ of the adipokine release by adipose tissue, except for adiponectin and leptin, could be attributed to nonfat cells [17]. (Figure 1.)

The list of known adipokines continues to increase. Maury et al. use medium-scale protein arrays and Enzyme-Linked ImmunoSorbent Assay (ELISA) to identify 6 novel adipokines as secretory products of human omental adipose tissue, which were enhanced in obesity: three chemokines (growth-related oncogen factor, RANTES [regulated upon activation, normal $\mathrm{T}$ cell expressed and secreted], macrophage inflammatory protein $[\mathrm{MIP}]-1 \beta)$, one interleukin (IL-7), one tissue inhibitor of metalloproteinases (TIMP-1), and one growth factor (thrombopoietin) [18]. Identifying novel adipokines that contribute to the pathogenesis of microvascular diseases in obesity and diabetes will increase our knowledge of the active role of adipose tissue in the regulation of microvascular function.

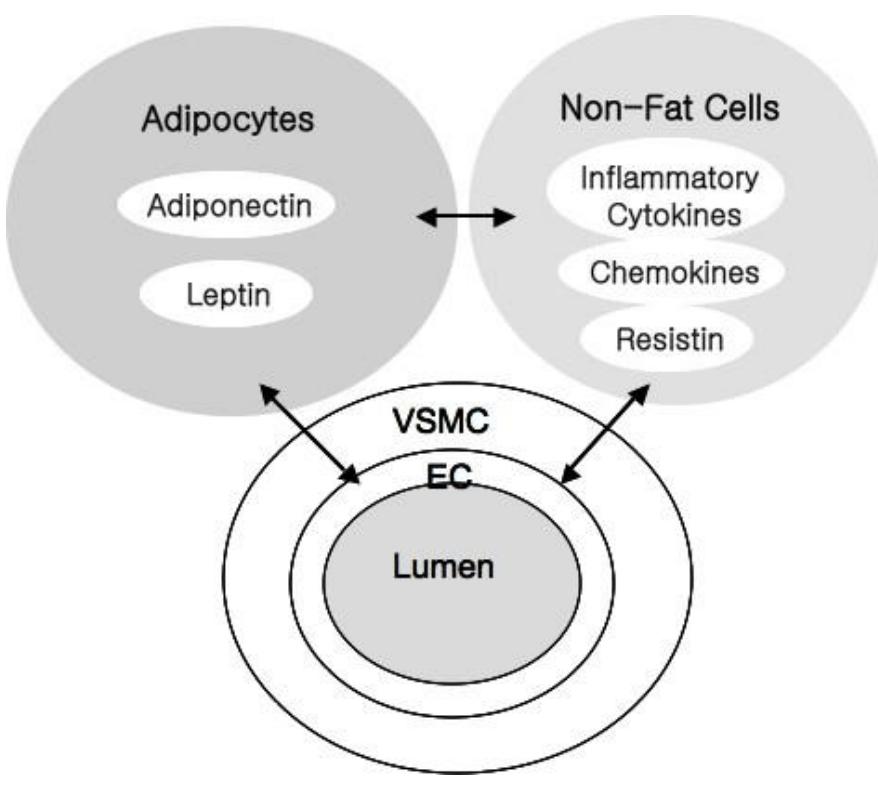

Figure 2. Crosstalk Between Perivascular Adipose and Vascular Cells. There is a crosstalk among adipocytes, T-lymphocytes, macrophages, endothelial cells (EC) and vascular smooth muscle cells (VSMC) in adipose tissue to regulate endothelial function and adipose tissue growth or remodeling.

\section{The active role of adipose tissue in microvascular dysfunction in obesity and type 2 diabetes}

The role of adipose tissue in the development of obesity and associated complications was considered to be a passive one until recently. We now understand that, in addition to storing energy in the form of triglycerides, adipose tissue also secretes a large variety of cytokines, chemokines and hormone-like factors [2]. The production of proatherogenic chemokines by adipose tissue is of particular interest, since their local secretion, for example by perivascular adipose depots, may provide a novel mechanistic link between obesity and obesity-associated vascular complications. (Figure 2)

\subsection{Adipose-derived Cytokines and Chemokines} and Microvascular Dysfunction

Adipose-derived cytokines and chemokines contribute to impaired vascular function in various microvasculature systems. In coronary circulation, TNF $\alpha$ leads to endothelial dysfuntion in coronary arterioles of diabetic mice $(\mathrm{db} / \mathrm{db})$ by inducing profound oxidative/nitrative stress evidenced by enhanced superoxide production and nitrotyrosine expression in the vessel wall [19]. Incubation of coronary arterioles with IL-6 (5 ng/ml) induced endothelial dysfunction in the presence of NGnitro-L-arginine methyl ester (L-NAME, endothelial nitric oxide synthase inhibitor) and indomethacin (cyclooxygenase inhibitor) in wild type mice, but anti-IL-6 restored acetycholine (ACh)-induced vasodilation in the presence of LNAME and indomechacin in $\mathrm{db} / \mathrm{db}$, suggesting that IL-6 decreased endothelial derived hyperpolarizing factor (EDHF)-mediated vasodilation in type 2 diabetes [20]. Anti-MCP-1 restored impaired endothelial function in diabetic mice coronary arterioles by ameliorating oxidative stress and inhibiting $\mathrm{TNF} \alpha$ expression. (Unpublished data) In cremaster arterioles, proinflammatory cytokines, such as IL-1 and 
TNF $\alpha$ leads to vascular dysfunction by altering leukocyte-endothelium interaction. IL-1 $\beta$ and TNF $\alpha$ separately induce and synergistically increase P-selectin-dependent leukocyte rolling and firm adhesion in mouse cremaster arterioles [21]. In the rabbit mesenteric vascular bed, IL-1 $\beta$ increases leukocyte rolling by the induction of $\mathrm{E}$ selectin on venular endothelium [22].

Muscle perfusion is an important regulator of insulin-mediated muscle glucose uptake, the main determinant of whole-body insulin sensitivity [23]. Insulin has been shown to increase muscle perfusion by acting directly on microvascular endothelium, and in muscle, this effect contributes to insulin-mediated glucose uptake [24]. Increased plasma level of TNF $\alpha$ is associated with impaired capillary recruitment in healthy subjects [25]. Moreover, TNF $\alpha$ directly inhibits insulinmediated capillary recruitment and insulinmediated glucose uptake in rat muscle [26]. TNF $\alpha$ directly impairs insulin's vasodilator effects in muscle resistance arteries of rats via activation of c-jun N-terminal kinase (JNK) and inhibition of insulin signaling in microvascular endothelium [27]. Similar to TNF $\alpha$, non-esterified fatty acids (NEFA) impair insulin-mediated capillary recruitment and glucose uptake in rat and human subjects [28, 29]. In addition to skeletal muscle, adipose has recently been demonstrated to profoundly contribute to the whole body glucose uptake [30]. Adipose selective targeting of the glucose transporter (GLUT4) gene impairs insulin action in muscle and liver, therefore increasing the risk of diabetes [30]. Hypothetically, insulinmediated adipose blood flow may affect adipose glucose uptake and insulin-induced vasodilation of adipose arterioles may be associated with adipose insulin sensitivity by regulating both hemodynamic and metabolic pathways. However, the role of insulin-induced vasodilation of adipose microcirculation in the regulation of adipose blood flow has received limited attention..

Due to the technical difficulties in studying the microvascular function in human subjects, our understanding of the association between adipokines and microvascular function relies primarily on animal studies. Since human coronary arterioles can be obtained from tissues removed from patients undergoing: cardiac surgery [31], human submucosal arterioles can be dissected from full-thickness intestinal specimens obtained from patients undergoing bowel operations [32], and human skeletal muscle and adipose arterioles can be obtained during elective abdominal or cardiac surgery [33, 34], studying the effects of various adipokines on arteriolar function in human subjects is feasible and may improve our understanding of the role of adiposederived factors in microvascular dysfunction in obese and type 2 diabetic patients.

\subsection{Inflammatory Cells Infiltration and} Microvascular Dysfunction

Obesity is associated with macrophage accumulation in white adipose tissue, where these infiltrating cells interact with adipocytes and endothelial cells, comprising a local inflammatory network [35]. This crosstalk results in the production of multiple cytokines and chemokines, such as TNFo and MCP-1, which activate, propagate and sustain the local inflammatory response in adipose tissue. Coenen et al. suggested that diet-induced increases in adiposity, but not plasma lipids, promote macrophage infiltration into white adipose tissue [35]. The extent of macrophage accumulation in white adipose tissue correlates with the degree of adiposity [35]. After gastric bypass surgery-induced weight loss, macrophage infiltration and chemoattractant gene expression are reduced in white adipose tissue of morbidly obese subjects [36]. Adipose macrophage infiltration is associated with insulin resistance and vascular endothelial dysfunction in obese subjects [6]. Furthermore, macrophage infiltration into adipose tissue promotes angiogenesis for adipose tissue remodeling in obesity [37]. This suggests there may be crosstalk between macrophages and endothelial cells in adipose tissue to regulate endothelial function and adipose tissue growth or remodeling.

In addition to macrophage, T-lymphocyte has recently been identified as a key player in adipose inflammation by orchestrating the inflammatory cascade evolution. In a mouse model of obesitymediated insulin resistance, high fat diet induced insulin resistance after 5 weeks, which was associated with a marked T-lymphocyte infiltration in visceral adipose tissue [38]. In 
contrast, recruitment of macrophages was delayed with an increase of MAC3 positive staining and F4/80 mRNA expression after 10 weeks of high fat diet, suggesting a dissociation of macrophage invasion into adipose tissue and insulin resistance initiation [38]. In patients with type 2 diabetes, lymphocyte content in adipose tissue biopsies significantly correlates with waist circumference, a marker of insulin resistance [38]. Immunohistochemical staining of human adipose tissue revealed the presence of mainly CD4 positive lymphocytes as well as macrophage infiltration. Most macrophages were HLA-DRpositive, reflecting activation via interferongamma (IFN $\gamma$ ), a cytokine released from CD4positive lymphocyte [38]. Therefore, proinflammatory T-lymphocyte are present in visceral adipose tissue and may contribute to local inflammatory cell activation before the appearance of macrophages, suggesting that T-lymphocytes play an important role in the initiation and perpetuation of adipose tissue inflammation [38]. However, there is no literature reporting an association between T-lymphocyte filtration and endothelial dysfunction in either animal models or clinical studies. We have gradually accepted that lymphocytes may play a central role in inflamed adipose inflammation by crosstalk among adipocyte, macrophage and endothelial cells, which produces multiple cytokines and chemokines, to further activate, propagate, and sustain the local inflammatory response in adipose tissue. However, direct evidence is necessary to clarify how the local inflammation network and systemic low grade inflammation participate in the regulation of vascular function and whether the direct infiltration of lymphocyte or macrophage into the vascular wall may be associated with microvascular dysfunction.

3.3 Adipose-derived Hormone-like Factors and Microvascular Dysfunction

Adipose-derived hormone like factors may include but are not limited to adiponectin, leptin and resistin. The release of resistin was 2.5-fold greater by explants of human omental adipose than by explants of human subcutaneous abdominal adipose tissue [39]. Resistin release by adipocytes was negligible as compared to that by the non-fat cells of adipose tissue [39]. Resistin impairs insulin-evoked vasodilation of mice small mesenteric arteries possibly by altering insulin receptor substrate (IRS)-1 tyrosine/serine phosphorylation and its consequent interaction with phosphatidylinositol 3-kinase (PI-3K) [40].

Leptin formation by adipocytes was 8-fold greater than its formation by non-fat cells [39]. Several studies suggest a "leptin paradox" as this adipokine is associated with both the activation and inhibition of nitric oxide (NO)-dependent vasodilation. This paradox is well explained by data showing that leptin-induced vasodilation occurred only in vitro at concentrations exceeding $160 \mathrm{ng} / \mathrm{ml}$ while leptin-induced endothelial dysfunction was found in vitro and in vivo at concentrations ranging from $10-90 \mathrm{ng} / \mathrm{ml}$ [41].

Plasma level of adiponectin was significantly lower in adult human subjects with obesity [42] and type 2 diabetes [43]. Adiponectin increases NO production in vascular endothelium by increasing Ser1177 phosphorylation of endothelial nitric oxide synthase (eNOS) via AMP activated protein kinase (AMPK) pathway [44]. Adiponectin also causes vasodilation of mesenteric rings by opening voltage-gated $\mathrm{K}$ channels $(\mathrm{Kv})$, suggesting that adiponectin induces both endothelial-dependent and endothelialindependent vasodilation. ${ }^{45}$ Our data suggest that adiponectin administration (subcutaneous injection) partially improved endothelialdependent vasodilation in coronary arterioles from ApoE knockout mice (ApoE -/-) or diabetic mice $(\mathrm{db} / \mathrm{db})$ and, indicating possible therapeutic effects of adiponectin in the pathogenesis of diabetes and atherosclerosis-related vascular dysfunction (unpublished data).

\section{The Endocrine Role of Adipose Tissue in Regulating Vascular Function}

The presence of fenestrated capillaries, one of the hallmarks of endocrine and exocrine organs that facilitate the release of products of adipose tissue into the bloodstream, has been reported in mouse adipose tissue [46]. This observation, though not yet subsequently confirmed, provides direct evidence that adipose tissue may play an endocrine role in the regulation of whole-body 
vascular physiology by secreting adipokines into circulation. Obesity and type 2 diabetes are characterized by a diminished production of protective factors such as adiponectin and an increase in detrimental adipokines such as leptin, resistin, IL-6, TNF $\alpha$, IL-17, MCP-1 and plasminogen activator inhibitor-1 (PAI-1) etc [47]. This dysregulation of adipose-derived factors in circulation not only contribute to the imbalance of vascular NO and superoxide production, but also regulate the immunosystem because chemokines, such as MIP-1 or RANTES, induce inflammation by stimulating the infiltration of T-lymphocytes and macrophages to the vessel wall [47]. (Figure 3)

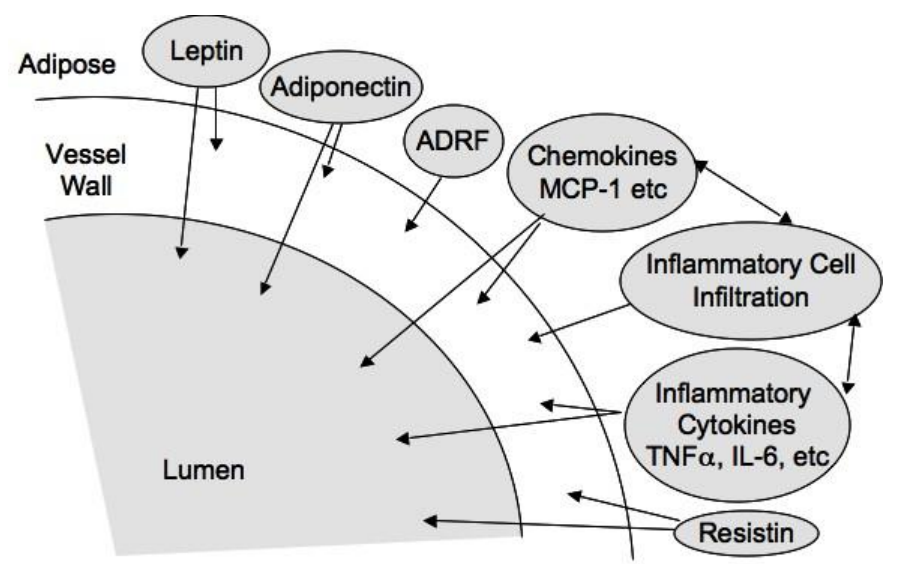

Figure 3. The Endocrine/Paracrine Role of Perivascular Adipose. The dysregulation of adipose-derived factors in circulation not only contributes to the systemic subclinical inflammation, but also regulates the immunosystem as chemokines, such as MCP-1 or RANTES, induce inflammation by stimulating the infiltration of T-lymphocytes and macrophages to the vessel wall. Thus, obesity and diabetes-related vascular dysfunction may well be caused by altered signaling from adipose tissue to blood vessels.

\section{The Paracrine Role of Adipose Tissue in Regulating Microvascular Function}

Adipose tissue microcirculation has been neglected because adipose tissue was considered to be poorly vascularized. In fact, the large size of mature adipocytes hinders the dense capillary network surrounding adipocyte [48], which suggests that there may be crosstalk between adipose tissue and adipose microvasculature.

There is controversy whether the role of perivascular adipose in regulating adipose microcirculation is beneficial or detrimental. Inflammatory cells infiltrating perivascular fat and adventitia may contribute to the release of the cytokine milieu, which in turn promotes vascular dysfunction. In contrast, recent studies confirm that inhibitory action of perivascular fat on mesenteric contractile responses to a variety of vasoconstrictors and the anticontractile effect is directly dependent on the amount of adipose tissue [49]. Thus the term "adipocyte-derived relaxing factor" (ADRF) was coined to characterize these substances [49]. Although adiponectin relaxes mesenteric rings by opening $\mathrm{Kv}$ channels, this is not ADRF derived, since adiponectin knockout mice showed no difference in anticontractile effects of perivascular adipose compared with the wild type control [45].

There may be a balance between the beneficial and detrimental role of perivascular adipose in regulating microcirculation. The transient effects of ADRF may contribute to the protective effects of adipose in the regulation of vascular tone and blood pressure. This effect can be attenuated during pathological conditions, as occurs in hypertension [50]. However, the chronic effects of inflamed adipose characterized by an adverse adipokines expression pattern typically with increased expression of inflammatory cytokines and chemokines may contribute to impaired microvascular function. (Figure 3)

\section{The Future Perspective}

In the context of the worldwide increase of obesity and its cardiovascular and metabolic complications, investigations focusing on the role of perivascular adipose tissue in obesity and type 2 diabetes-related microvascular disease provide a new field of study. Future research is needed to 1) identify the novel adipokines that potentially contribute to the pathogenesis of vascular dysfunction in obesity and diabetes, 2) compare protein profiling of adipokines secreted by perivascular adipose tissue from healthy and diabetic subjects, 3) evaluate the respective contribution of adipocytes and non-fat cells in 
adipose tissue to the adipokine secretion, 4) examine the relative importance of various fat deposit in contributing to the local and systemic low-grade inflammation, 5) elucidate the paracrine role of adipokines in affecting microvascular function in human subjects, 6) assess the effects of life style management (such as calorie restriction and exercise), diet supplement and pharmacological intervention on body weight, adiposity and adipokine expression profile, and, 7) provide direct evidence that the modulation of adverse adipokine expression patterns leads to the improvement of microvascular function in diabetic patients. Results from these studies will improve our understanding of the physiological functions and therapeutic potential of perivascular adipose in the microvascular dysfunction of obesity and type 2 diabetic patients.

\section{Concluding Remarks}

Perivascular adipose tissue regulates vascular function in obese and type 2 diabetics by endocrine and paracrine effects of adipokines produced via the crosstalk among inflammatory cells, adipocytes and vascular cells. This insight allows us to clearly define the role adipose plays in microvascular dysfunction in obesity and diabetes and how inflammatory mediators act as signaling molecules in this process. Moreover, on a molecular level, we are beginning to comprehend how such variables as hormonal control, exercise, diet supplement and weight-loss surgery interact and result in the change in the adipokine expression pattern by adipose tissue, and how pharmacological intervention may modulate adipose tissue biology, and thereby regulate obesity and diabetes-associated microvascular disorders.

\section{Funding Sources}

This study was supported by grants from American Heart Association Scientist Development Grant (110350047A), Pfizer Atorvastatin Research Award (2004-37) and NIH grants (RO1-HL077566 and RO1-HL085119) to Dr. Cuihua Zhang.

\section{Abbreviation:}

ADRF, adipocyte-derived relaxing factor; AMPK, AMP activated protein kinase; EDHF, endothelial derived hyperpolarizing factor; eNOS, endothelial nitric oxide synthase; GLUT, glucose transporter; HB-EGF, heparin-binding epidermal growth factor-like growth factor; IFN $\gamma$, interferongamma; IL, interleukin; IRS, insulin receptor substrate; JNK, c-jun N-terminal kinase; Kv, voltage-gated $\mathrm{K}$ channels; MCP-1, monocyte chemoattractant protein-1; MIF, macrophage inhibitory factor; MIP1 $\beta$, macrophage inflammatory protein; NEFA, non-esterified fatty acids; NO, nitric oxide; PAI-1, plasminogen activator inhibitor-1; PI-3K, phosphoinositide 3kinase; RANTES, regulated upon activation, normal $\mathrm{T}$ cell expressed and secreted; TGF $\beta$, transforming growth factor-beta, TIMP-1, tissue inhibitor of metalloproteinases; $\mathrm{TNF} \alpha$, tumor necrosis factor-alpha; VEGF, vascular endothelial growth factor.

\section{References}

1. Hajer GR, van Haeften TW, Visseren FL. Adipose tissue dysfunction in obesity, diabetes, and vascular diseases. Eur Heart J. 2008.

2. Kershaw EE, Flier JS. Adipose tissue as an endocrine organ. J Clin Endocrinol Metab. 2004;89(6):2548-2556.

3. Eringa EC, Bakker W, Smulders YM, Serne EH, Yudkin JS, Stehouwer CD. Regulation of vascular function and insulin sensitivity by adipose tissue: focus on perivascular adipose tissue. Microcirculation. 2007;14(4-5):389402.

4. Chandrasekar B, Boylston WH, Venkatachalam K, Webster NJ, Prabhu SD, Valente AJ. Adiponectin blocks interleukin18-mediated endothelial cell death via APPL1dependent AMP-activated protein kinase (AMPK) activation and IKK/NFkappaB/PTEN suppression. $J$ Biol Chem. 2008;283(36):24889-24898.

5. Wexler DJ, Hu FB, Manson JE, Rifai N, Meigs JB. Mediating effects of inflammatory biomarkers on insulin resistance associated 
with obesity. Obes Res. 2005;13(10):17721783.

6. Apovian CM, Bigornia S, Mott M, Meyers MR, Ulloor J, Gagua M, McDonnell M, Hess D, Joseph L, Gokce N. Adipose macrophage infiltration is associated with insulin resistance and vascular endothelial dysfunction in obese subjects. Arterioscler Thromb Vasc Biol. 2008;28(9):1654-1659.

7. Goldstein BJ, Scalia R. Adipokines and vascular disease in diabetes. Curr Diab Rep. 2007;7(1):25-33.

8. Marcus Y, Stern N. Fat cell-derived modulators of vascular cell pathophysiology: the list keeps growing. J Cardiometab Syndr. 2006;1(2):121-124.

9. Linder K, Arner P, Flores-Morales A, TolletEgnell P, Norstedt G. Differentially expressed genes in visceral or subcutaneous adipose tissue of obese men and women. J Lipid Res. 2004;45(1):148-154.

10. Vohl MC, Sladek R, Robitaille J, Gurd S, Marceau P, Richard D, Hudson TJ, Tchernof A. A survey of genes differentially expressed in subcutaneous and visceral adipose tissue in men. Obes Res. 2004;12(8):1217-1222.

11. He G, Pedersen SB, Bruun JM, Lihn AS, Jensen PF, Richelsen B. Differences in plasminogen activator inhibitor 1 in subcutaneous versus omental adipose tissue in non-obese and obese subjects. Horm Metab Res. 2003;35(3):178-182.

12. Douchi T, Iwamoto I, Yoshimitsu N, Ohishi Y, Nagata Y. Differences in leptin production by regional fat mass in postmenopausal women. Endocr J. 2002;49(4):413-416.

13. van Harmelen V, Dicker A, Ryden M, Hauner H, Lonnqvist F, Naslund E, Arner P. Increased lipolysis and decreased leptin production by human omental as compared with subcutaneous preadipocytes. Diabetes. 2002;51(7):2029-2036.

14. Arner P. Regional differences in protein production by human adipose tissue. Biochem Soc Trans. 2001;29(Pt 2):72-75.

15. MacLaren R, Cui W, Simard S, Cianflone K. Influence of obesity and insulin sensitivity on insulin signaling genes in human omental and subcutaneous adipose tissue. J Lipid Res. 2008;49(2):308-323.

16. Gomez-Ambrosi J, Catalan V, Diez-Caballero A, Martinez-Cruz LA, Gil MJ, GarciaFoncillas J, Cienfuegos JA, Salvador J, Mato JM, Fruhbeck G. Gene expression profile of omental adipose tissue in human obesity. FASEB J. 2004;18(1):215-217.

17. Fain JN, Madan AK, Hiler ML, Cheema P, Bahouth SW. Comparison of the release of adipokines by adipose tissue, adipose tissue matrix, and adipocytes from visceral and subcutaneous abdominal adipose tissues of obese humans. Endocrinology. 2004;145(5):2273-2282.

18. Maury E, Ehala-Aleksejev K, Guiot Y, Detry R, Vandenhooft A, Brichard SM. Adipokines oversecreted by omental adipose tissue in human obesity. Am J Physiol Endocrinol Metab. 2007;293(3):E656-665.

19. Gao X, Belmadani S, Picchi A, Xu X, Potter BJ, Tewari-Singh N, Capobianco S, Chilian WM, Zhang C. Tumor necrosis factor-alpha induces endothelial dysfunction in $\operatorname{Lepr}(\mathrm{db})$ mice. Circulation. 2007;115(2):245-254.

20. Park Y, Capobianco S, Gao X, Falck JR, Dellsperger KC, Zhang C. Role of EDHF in type 2 diabetes-induced endothelial dysfunction. Am J Physiol Heart Circ Physiol. 2008;295(5):H1982-1988.

21. Thorlacius H, Lindbom L, Raud J. Cytokineinduced leukocyte rolling in mouse cremaster muscle arterioles in P-selectin dependent. Am J Physiol. 1997;272(4 Pt 2):H1725-1729.

22. Olofsson AM, Arfors KE, Ramezani L, Wolitzky BA, Butcher EC, von Andrian UH. E-selectin mediates leukocyte rolling in interleukin-1-treated rabbit mesentery venules. Blood. 1994;84(8):2749-2758.

23. Bonadonna RC, Saccomani MP, Del Prato S, Bonora E, DeFronzo RA, Cobelli C. Role of tissue-specific blood flow and tissue recruitment in insulin-mediated glucose uptake of human skeletal muscle. Circulation. 1998;98(3):234-241.

24. Eringa EC, Stehouwer CD, Merlijn T, Westerhof N, Sipkema P. Physiological concentrations of insulin induce endothelinmediated vasoconstriction during inhibition of 
NOS or PI3-kinase in skeletal muscle arterioles. Cardiovasc Res. 2002;56(3):464471.

25. de Jongh RT, Ijzerman RG, Serne EH, Voordouw JJ, Yudkin JS, de Waal HA, Stehouwer CD, van Weissenbruch MM. Visceral and truncal subcutaneous adipose tissue are associated with impaired capillary recruitment in healthy individuals. $J$ Clin Endocrinol Metab. 2006;91(12):5100-5106.

26. Youd JM, Rattigan S, Clark MG. Acute impairment of insulin-mediated capillary recruitment and glucose uptake in rat skeletal muscle in vivo by TNF-alpha. Diabetes. 2000;49(11):1904-1909.

27. Eringa EC, Stehouwer CD, Walburg K, Clark $\mathrm{AD}$, van Nieuw Amerongen GP, Westerhof N, Sipkema P. Physiological concentrations of insulin induce endothelin-dependent vasoconstriction of skeletal muscle resistance arteries in the presence of tumor necrosis factor-alpha dependence on c-Jun N-terminal kinase. Arterioscler Thromb Vasc Biol. 2006;26(2):274-280.

28. de Jongh RT, Serne EH, Ijzerman RG, de Vries G, Stehouwer CD. Free fatty acid levels modulate microvascular function: relevance for obesity-associated insulin resistance, hypertension, and microangiopathy. Diabetes. 2004;53(11):2873-2882.

29. Clerk LH, Rattigan S, Clark MG. Lipid infusion impairs physiologic insulin-mediated capillary recruitment and muscle glucose uptake in vivo. Diabetes. 2002;51(4):11381145.

30. Abel ED, Peroni O, Kim JK, Kim YB, Boss O, Hadro E, Minnemann T, Shulman GI, Kahn BB. Adipose-selective targeting of the GLUT4 gene impairs insulin action in muscle and liver. Nature. 2001;409(6821):729-733.

31. Miura H, Wachtel RE, Loberiza FR, Jr., Saito T, Miura M, Nicolosi AC, Gutterman DD. Diabetes mellitus impairs vasodilation to hypoxia in human coronary arterioles: reduced activity of ATP-sensitive potassium channels. Circ Res. 2003;92(2):151-158.

32. Hatoum OA, Binion DG, Miura H, Telford G, Otterson MF, Gutterman DD. Role of hydrogen peroxide in ACh-induced dilation of human submucosal intestinal microvessels. Am $J$ Physiol Heart Circ Physiol. 2005;288(1):H48-54.

33. Phillips SA, Hatoum OA, Gutterman DD. The mechanism of flow-induced dilation in human adipose arterioles involves hydrogen peroxide during CAD. Am J Physiol Heart Circ Physiol. 2007;292(1):H93-100.

34. Liu Y, Sellke EW, Feng J, Clements RT, Sodha NR, Khabbaz KR, Senthilnathan V, Alper SL, Sellke FW. Calcium-activated potassium channels contribute to human skeletal muscle microvascular endothelial dysfunction related to cardiopulmonary bypass. Surgery. 2008;144(2):239-244.

35. Coenen KR, Gruen ML, Chait A, Hasty AH. Diet-induced increases in adiposity, but not plasma lipids, promote macrophage infiltration into white adipose tissue. Diabetes. 2007;56(3):564-573.

36. Cancello R, Henegar C, Viguerie N, Taleb S, Poitou C, Rouault C, Coupaye M, Pelloux V, Hugol D, Bouillot JL, Bouloumie A, Barbatelli G, Cinti S, Svensson PA, Barsh GS, Zucker JD, Basdevant A, Langin D, Clement K. Reduction of macrophage infiltration and chemoattractant gene expression changes in white adipose tissue of morbidly obese subjects after surgery-induced weight loss. Diabetes. 2005;54(8):2277-2286.

37. Pang C, Gao Z, Yin J, Zhang J, Jia W, Ye J. Macrophage infiltration into adipose tissue may promote angiogenesis for adipose tissue remodeling in obesity. Am $J$ Physiol Endocrinol Metab. 2008;295(2):E313-322.

38. Kintscher U, Hartge M, Hess K, ForystLudwig A, Clemenz M, Wabitsch M, FischerPosovszky P, Barth TF, Dragun D, Skurk T, Hauner $\mathrm{H}$, Bluher $\mathrm{M}$, Unger T, Wolf AM, Knippschild U, Hombach V, Marx N. Tlymphocyte infiltration in visceral adipose tissue: a primary event in adipose tissue inflammation and the development of obesitymediated insulin resistance. Arterioscler Thromb Vasc Biol. 2008;28(7):1304-1310.

39. Fain JN, Cheema PS, Bahouth SW, Lloyd Hiler M. Resistin release by human adipose tissue explants in primary culture. Biochem Biophys Res Commun. 2003;300(3):674-678. 
40. Gentile MT, Vecchione C, Marino G, Aretini A, Di Pardo A, Antenucci G, Maffei A, Cifelli G, Iorio L, Landolfi A, Frati G, Lembo G. Resistin impairs insulin-evoked vasodilation. Diabetes. 2008;57(3):577-583.

41. Tune JD, Considine RV. EFFECTS OF LEPTIN ON CARDIOVASCULAR PHYSIOLOGY. $J$ Am Soc Hypertens. 2007;1(4):231-241.

42. Arita Y, Kihara S, Ouchi N, Takahashi M, Maeda K, Miyagawa J, Hotta K, Shimomura I, Nakamura T, Miyaoka K, Kuriyama H, Nishida M, Yamashita S, Okubo K, Matsubara K, Muraguchi M, Ohmoto Y, Funahashi T, Matsuzawa Y. Paradoxical decrease of an adipose-specific protein, adiponectin, in obesity. Biochem Biophys Res Commun. 1999;257(1):79-83.

43. Hotta K, Funahashi T, Arita Y, Takahashi M, Matsuda M, Okamoto Y, Iwahashi H, Kuriyama H, Ouchi N, Maeda K, Nishida M, Kihara S, Sakai N, Nakajima T, Hasegawa K, Muraguchi M, Ohmoto Y, Nakamura T, Yamashita S, Hanafusa T, Matsuzawa Y. Plasma concentrations of a novel, adiposespecific protein, adiponectin, in type 2 diabetic patients. Arterioscler Thromb Vasc Biol. 2000;20(6):1595-1599.

44. Cheng KK, Lam KS, Wang Y, Huang Y, Carling $\mathrm{D}, \mathrm{Wu} \mathrm{D}$, Wong $\mathrm{C}, \mathrm{Xu} \mathrm{A}$. Adiponectin-induced endothelial nitric oxide synthase activation and nitric oxide production are mediated by APPL1 in endothelial cells. Diabetes. 2007;56(5):1387-1394.

45. Fesus G, Dubrovska G, Gorzelniak K, Kluge R, Huang Y, Luft FC, Gollasch M. Adiponectin is a novel humoral vasodilator. Cardiovasc Res. 2007;75(4):719-727.

46. Cao R, Brakenhielm E, Wahlestedt C, Thyberg $\mathrm{J}$, Cao Y. Leptin induces vascular permeability and synergistically stimulates angiogenesis with FGF-2 and VEGF. Proc Natl Acad Sci U $S$ A. 2001;98(11):6390-6395.

47. Guzik TJ, Marvar PJ, Czesnikiewicz-Guzik M, Korbut R. Perivascular adipose tissue as a messenger of the brain-vessel axis: role in vascular inflammation and dysfunction. $J$ Physiol Pharmacol. 2007;58(4):591-610.

48. Sengenes C, Miranville A, Lolmede K, Curat $\mathrm{CA}$, Bouloumie A. The role of endothelial cells in inflamed adipose tissue. J Intern Med. 2007;262(4):415-421.

49. Lohn M, Dubrovska G, Lauterbach B, Luft FC, Gollasch M, Sharma AM. Periadventitial fat releases a vascular relaxing factor. FASEB J. 2002;16(9):1057-1063.

50. Galvez B, de Castro J, Herold D, Dubrovska G, Arribas S, Gonzalez MC, Aranguez I, Luft FC, Ramos MP, Gollasch M, Fernandez Alfonso MS. Perivascular adipose tissue and mesenteric vascular function in spontaneously hypertensive rats. Arterioscler Thromb Vasc Biol. 2006;26(6):1297-1302. 